\title{
Improved biological performance of magnesium by micro-arc oxidation
}

\author{
W.H. Ma, Y.J. Liu, W. Wang and Y.Z. Zhang \\ The Third Hospital of Hebei Medical University, The Provincial Key Laboratory for Orthopedic Biomechanics of Hebei, \\ Shijiazhuang, Hebei Province, China
}

\begin{abstract}
Magnesium and its alloys have recently been used in the development of lightweight, biodegradable implant materials. However, the corrosion properties of magnesium limit its clinical application. The purpose of this study was to comprehensively evaluate the degradation behavior and biomechanical properties of magnesium materials treated with micro-arc oxidation (MAO), which is a new promising surface treatment for developing corrosion resistance in magnesium, and to provide a theoretical basis for its further optimization and clinical application. The degradation behavior of MAO-treated magnesium was studied systematically by immersion and electrochemical tests, and its biomechanical performance when exposed to simulated body fluids was evaluated by tensile tests. In addition, the cell toxicity of MAO-treated magnesium samples during the corrosion process was evaluated, and its biocompatibility was investigated under in vivo conditions. The results of this study showed that the oxide coating layers could elevate the corrosion potential of magnesium and reduce its degradation rate. In addition, the MAO-coated sample showed no cytotoxicity and more new bone was formed around it during in vivo degradation. MAO treatment could effectively enhance the corrosion resistance of the magnesium specimen and help to keep its original mechanical properties. The MAO-coated magnesium material had good cytocompatibility and biocompatibility. This technique has an advantage for developing novel implant materials and may potentially be used for future clinical applications.
\end{abstract}

Key words: Magnesium; Micro-arc oxidation; Biodegradable; Biocompatibility; Mechanical properties; Corrosion

\section{Introduction}

One desirable characteristic of an implant for bone fracture fixation is its ability to degrade after the bone has healed. Otherwise, a second surgery is usually conducted to remove the implant. Long-term adverse effects or even an increased risk of local inflammation may occur after longterm implantation, because the metallic implant is a foreign body to human tissues. However, repeated surgeries not only increase the morbidity rate of patients, but also result in increased health-care costs and longer hospitalizations (1). To reduce such complications, biomaterial engineers have become interested in developing biodegradable metallic devices (2-4).

Owing to their degradation properties, magnesium and its alloys are being actively investigated as potential loadbearing orthopedic implant materials (5-8). Various magnesium alloys have been developed, some of which have shown good biocompatibility. However, the major obstacles of the clinical use of magnesium-based materials are its rapid corrosion rate and the release of hydrogen gas upon degradation (9). It has been reported that the mechanical integrity of magnesium alloy was only maintained for 6-8 weeks, with the release of hydrogen during the corrosion process (10). Therefore, in order to develop the corrosion resistance of magnesium, different modification methods, such as alloying and various surface treatments, have been introduced $(9,11)$. For example, Witte et al. (12) reported that magnesium alloys AZ31 and AZ91 could enhance the osteogenesis response and increase newly formed bone. Xu et al. (13) also reported that the Mg-Mn-Zn alloy demonstrated good in vivo degradation behavior with bone implants. However, it should be noted that most of the reported biomedical magnesium alloys contain aluminum and/or rare earth elements. It is well known that aluminum is harmful to neurons and osteoblasts, and is also associated with dementia and Alzheimer's disease $(14,15)$. The addition of rare earth metals such as zirconium and cerium into the magnesium substrate may potentially be toxic to cells $(16,17)$ and may lead to hepatotoxicity or have adverse effects on DNA transcription factors $(18,19)$. Consequently, aluminum and rare earth elements are unsuitable alloying elements for biomedical magnesium materials, particularly when they are above their normal levels. Several authors have pointed out that $\mathrm{Ca}, \mathrm{Mn}$, and $\mathrm{Zn}$ could be appropriate candidates. Further research has demonstrated that $\mathrm{Mg}-\mathrm{Ca}$

Correspondence: Yingze Zhang: <zyz9820@163.com>.

Received June 18, 2014. Accepted October 6, 2014. First published online December 19, 2014. 
(4), Mg-Zn (20), and Mg-Mn-Zn (13) alloys gradually degraded within bone and had good biocompatibility both in vitro and in vivo; however, the changes in the mechanical properties of these alloys during degradation were not addressed.

Apart from alloying, surface modifications to improve the corrosion properties of magnesium alloys, such as micro-arc oxidation (MAO), ion implantation, and plasma anodization, have been investigated (21). Of all of these methods, MAO is a promising new surface treatment method that can improve corrosion resistance, wear resistance, and the micro-hardness of magnesium alloys (22).

Thus, in this study, oxide coating layers were synthesized on a commercially available pure magnesium substrate using the MAO method, so as to improve biocompatibility and reduce the degradation rate. The corrosion properties of MAO-treated magnesium were investigated under both in vitro and in vivo conditions and addressed the cytocompatibility and mechanical integrity of treated samples during degradation.

\section{Material and Methods}

\section{Sample preparation}

Commercially available pure magnesium (Institute of Metal, Chinese Academy of Sciences, China) was used in this study. Disc samples $(11.3 \mathrm{~mm}$ in diameter and $3 \mathrm{~mm}$ thick) were prepared for the electrochemical corrosion test, the immersion test, and in vitro studies. Cylindrical rods for mechanical testing were $5 \mathrm{~mm}$ in diameter and $25 \mathrm{~mm}$ in gauge length, and, for the in vivo animal study, the tube samples were $6 \mathrm{~mm}$ in external diameter, $4 \mathrm{~mm}$ in internal diameter, and $5 \mathrm{~mm}$ in length. Prior to the MAO process, all samples were first mechanically polished with waterproof abrasive paper (up to 1200 grits) to remove the oxide, degreased with acetone, and then ultrasonically cleaned with ethanol and distilled water, sequentially. Before the in vitro cytotoxicity and in vivo degradation experiments, all samples were sterilized with $29 \mathrm{kGy}$ of ${ }^{60} \mathrm{Co}$ radiation.

A MAO coating was prepared on the magnesium surface using the MAO procedure, which was carried out with a constant current density for 10-40 min. After treatment, the surface of the specimen appeared to be uniformly oxidized. The specimens were then washed with distilled water and air-dried at room temperature.

\section{In vitro degradation tests}

In order to evaluate the in vitro degradation properties, electrochemical measurements and immersion tests were performed in a standard simulated body fluid (SBF) (23) at $\mathrm{pH} 7.4$, and the temperature was maintained at $37 \pm 0.5^{\circ} \mathrm{C}$.

Electrochemical measurements. Electrochemical measurements were performed with a three-electrode system (PARSTAT-2273; Princeton Applied Research, USA). A saturated calomel electrode was used as reference. Potentiodynamic polarization curves were measured at a scan rate of $1 \mathrm{mV} / \mathrm{s}$. Electrochemical impedance spectroscopy (EIS) analysis was also performed at open-circuit potential with a perturbing signal of $5 \mathrm{mV}$. The frequency varied from 100 to $1 \mathrm{MHz}$, and all the EIS results were fitted and analyzed using the Powersuit software (Agilent, USA).

Immersion tests. Immersion tests were carried out to conform with ASTM-G31-72 (24) (the ratio of surface area to solution volume was $1 \mathrm{~cm}^{2}: 30 \mathrm{~mL}$ ). Every $24 \mathrm{~h}$, the SBF was changed to ensure that the $\mathrm{pH}$ remained near physiological values. Samples were removed after $6 \mathrm{~h}$, and $1,3,7,14$, and 30 days of immersion, rinsed with distilled water, and dried at room temperature.

After the samples had been immersed for 3 and 14 days, surface morphology was observed using a scanning electronic microscope (Hitachi S-4800, Japan) with an energy dispersive spectrometer (EDS; Inca-356, England), and X-ray diffraction analysis (XRD; Bruker AXS-D8, Germany) was used to examine the composition of the corrosion products.

Finally, the samples were cleaned with chromic acid to remove the corrosion products, and the degradation rates (in units of $\mathrm{mm} / \mathrm{year}$ ) were obtained according to ASTMG31-72. The corrosion rate is given by the equation: Corrosion rate $=K W / A D T$, where the coefficient $K=8.76 \times 10^{4}$, $W$ is the weight loss (g), $A$ is the sample area exposed to solution $\left(\mathrm{cm}^{2}\right), T$ is the exposure time (h), and $D$ is the density of the material $\left(\mathrm{g} / \mathrm{cm}^{3}\right)(24)$.

The $\mathrm{pH}$ value of the solution was recorded during immersion tests (PHS-3C pH meter, Leici, China), and the release of hydrogen gas during degradation was also measured.

\section{Mechanical properties}

Tension tests were carried out with a CMT5105 universal testing machine (Shengzhen, China), according to GB/T 228-2002 (China). The tensile samples had a gauge length of $25 \mathrm{~mm}$. The samples were immersed in SBF using the same protocol as described for the immersion test, and mechanical properties were monitored at 6 different times ( $6 \mathrm{~h}$, and $1,3,7,14$, and 30 days). A testing speed of $0.5 \mathrm{~mm} / \mathrm{min}$ was used, and the yield strengths of the coated and uncoated samples during degradation were determined and compared.

\section{Cytotoxicity assessments}

Saos-2 cells were cultured in Dulbecco's modified Eagle's medium (DMEM; Gibco, USA), supplemented with $10 \%$ fetal bovine serum in a humidified incubator at $95 \%$ relative humidity and $5 \% \mathrm{CO}_{2}$ at $37^{\circ} \mathrm{C}$. Cytotoxicity was determined by indirect contact. Extracts of the coated and uncoated samples were prepared according to GB/T 16886.5. The extraction media were serially diluted to $50 \%$ and $25 \%$ concentrations after $72 \mathrm{~h}$ of incubation in a humidified atmosphere with $5 \% \mathrm{CO}_{2}$ at $37^{\circ} \mathrm{C}$.

Cell proliferation and viability. Cell proliferation and viability were measured with the 3-(4,5-dimethylthiazol-2 
-yl)-2,5-diphenyltetrazolium bromide (MTT) assay. Cells were incubated in 96-well flat-bottomed cell culture plates at $2.5 \times 10^{4}$ cells $/ \mathrm{mL}$ medium in each well and incubated for $24 \mathrm{~h}$ to allow cell attachment. The medium was then replaced by $100 \mu \mathrm{L}$ extraction medium of a different concentration. After 24, 48, and $72 \mathrm{~h}, 20 \mu \mathrm{L}$ of $5 \mathrm{mg} / \mathrm{mL}$ MTT solution (Sigma) was added to each well and incubated in a humidified atmosphere of $5 \% \mathrm{CO}_{2}$ at $37^{\circ} \mathrm{C}$ for $4 \mathrm{~h}$. Subsequently, $150 \mu \mathrm{L}$ DMSO was added to each well and absorbance measurements were conducted at $490 \mathrm{~nm}$ using a Synergy H4 Hybrid Microplate Reader (Bio-Tek, USA). DMEM was used as the negative control, and 5-fluorouracil (Qilu Pharmaceutical Co., Ltd., China) was used as the positive control.

Fluorescent staining of cells. Cells $\left(5 \times 10^{4}\right)$ were seeded onto 12-well plates, incubated for $24 \mathrm{~h}$, and treated with extraction media of different concentrations. DMEM was used as the negative control, and 5\% DMSO (Sigma, USA) was used as the positive control. After $72 \mathrm{~h}$, the cells were stained with Hoechst 33258 staining solution according to the manufacturer's instructions (Beyotime, China) and then observed with a fluorescence microscope (Imager A2, Carl Zeiss, Germany).

In vivo degradation and biocompatibility experiments Surgery. Animal tests were approved by the Ethics Committee of the Third Hospital of Hebei Medical University, and the in vivo degradation experiments were performed in the animal laboratory at the hospital. A total of 12 six-monthold male New Zealand rabbits (Laboratory Animal Center of Hebei Medical University) with an average body weight of 2.5-2.8 kg were used. The rabbits were randomly divided into 2 groups, and the chosen operation site was the right femoral condyle. In the experimental group, an MAO-coated magnesium stent was used, and an uncoated magnesium stent was implanted in the control group. Rabbits were anesthetized with $30 \mathrm{mg} / \mathrm{kg}$ sodium pentobarbital (Shanghai Xinya Pharmaceutics Ltd., China) by intravenous injection. The surgical site was cleaned with $0.9 \%$ saline and $75 \%$ ethanol. After anesthesia, a tiny incision was made at the surgical site of each rabbit. A hole $6 \mathrm{~mm}$ in depth and $6 \mathrm{~mm}$ in diameter was drilled into the right femoral condyle, and the stent was implanted into the prepared hole. The wound was rinsed with saline and sutured layer by layer, and then an aseptic dressing was applied over the incision. All animals received a subcutaneous injection of $1 \mathrm{mg} / \mathrm{kg}$ penicillin as an anti-inflammatory drug. The rabbits were sacrificed 3 months postoperatively.

Biochemical tests. During the experiments, 5-mL blood samples were taken from the helix vessel of the rabbits before surgery and at $1,2,4,8$, and 12 weeks after surgery. The blood biochemical tests, including serum magnesium, serum creatinine (CREA), blood urea nitrogen (BUN), and alanine aminotransferase (ALT), were performed with an automatic biochemical analyzer (Olympus AU 5400, Japan).
Radiographic and histological evaluation. Radiographs or computed tomography (CT) images were used to observe the in vivo degradation process at 8 and 12 weeks. Meanwhile, heart, kidney, spleen, and liver tissues from the rabbits were also inspected with hematoxylin and eosin staining (Beyotime) 12 weeks after surgery to verify whether degradation of the magnesium had harmed these important visceral organs. In addition, the bone samples with implants were harvested and fixed in 10\% formaldehyde for 3 days, dehydrated with 70,95 , and $100 \%$ ethanol, and then embedded in methyl methacrylate (Merck, Germany). Whole embedded samples were scanned in a micro-CT device (Inveon Micro-CT, Siemens, Germany) to view the extent of degradation of the stents and new bone growth. Afterwards, the embedded samples were cut into sections and then micro-ground down to 50-70- $\mu \mathrm{m}$ thickness. The sectioned samples were stained with methylene blue and fuchsin (Merck), and the interaction between bone and implants was observed under a light microscope (Axio Lab. A1, Carl Zeiss).

\section{Statistical analysis}

The two-sample $t$-test was used to determine whether any significant difference existed in the cytotoxicity and blood biochemical experiments. The software package SAS (version 9.1, SAS Institute Inc., USA) was used for the statistical analysis. Statistical significance was assigned to $P<0.05$.

\section{Results}

\section{In vitro degradation tests}

Electrochemical measurements. Figure 1A shows typical polarization curves for MAO-coated magnesium and pure magnesium. It shows that the corrosion current $\left(I_{\text {corr }}\right)$ value of MAO-coated magnesium was clearly less than that of pure magnesium, which indicated that coated magnesium was less susceptible to corrosion. Nyquist plots and the polarization resistance $(R p)$ of samples are shown in Figure 1B: the higher the $R p$, the lower the corrosion rate (25). The Rp of MAO-coated magnesium was higher than that of pure magnesium, which was consistent with the $I_{\text {corr }}$ data, showing that the rate of electrochemical degradation of the coated magnesium was slower than that of pure magnesium. These results of electrochemical tests suggested that the MAO coating could effectively protect the magnesium metal from corrosion.

Immersion experiments. Surface morphologies of pure magnesium and MAO-coated magnesium after 3 and 14 days of immersion are shown in Figure 2. MAO-treated magnesium degraded more slowly than pure magnesium, which was in good agreement with the electrochemical results. As shown in Figure $2 \mathrm{C}$ and $\mathrm{D}$, pure magnesium samples experienced pitting corrosion and were covered with partially protective corrosion products, but obvious corrosion was not found on the MAO-coated magnesium 

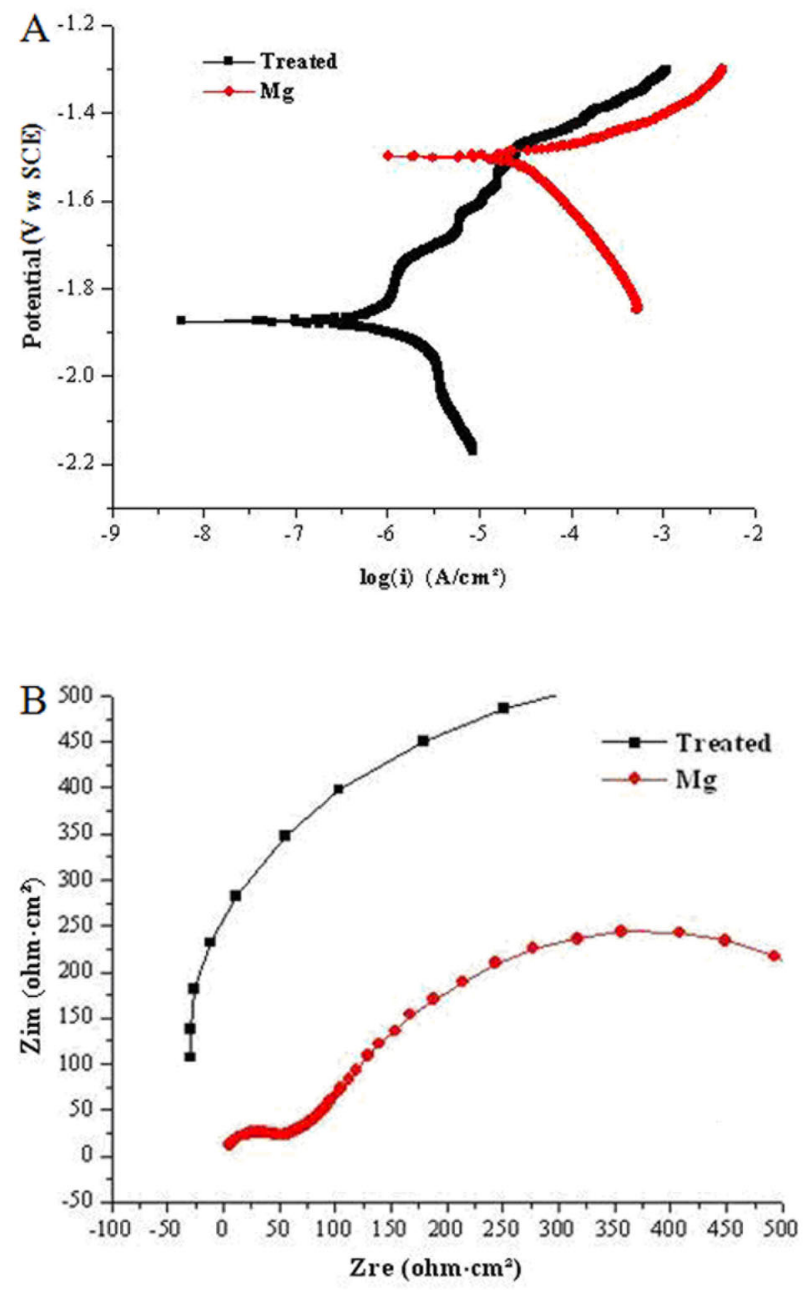

Figure 1. Electrochemical measurements. $A$, Polarization curves. $B$. Nyquist plots of $\mathrm{Mg}$ and MAO-treated Mg. MAO: micro-arc oxidation; Zre: real part of impedance; Zim: Imaginary part of impedance.

samples, and there were very small quantities of corrosion product deposits on the surface of those samples. EDS results for the surface corrosion products on those metal samples are illustrated in Figure 3. Also, a number of cracks were observed on the surface of the pure magnesium samples after 14 days of immersion (Figure 3A). The EDS results revealed that the surface corrosion products (marked area in Figure 3) were rich in $\mathrm{O}, \mathrm{Mg}, \mathrm{P}$, and $\mathrm{Ca}$. Further XRD results suggested that magnesium hydroxide $\left[\mathrm{Mg}(\mathrm{OH})_{2}\right]$ and hydroxyapatite $(\mathrm{HA})$ precipitated onto the magnesium surface (Figure 4A), and magnesium oxide [MgO] precipitated onto the MAO-coated magnesium surface (Figure 4B). Furthermore, a strong background and broadened peaks can be observed in Figure 4A and B, which might be due to the presence of amorphous corrosion products as indicated by Kuwahara et al. (26).
Figure 5A shows the $\mathrm{pH}$ variation of immersion tests; the $\mathrm{pH}$ rose rapidly (from 7.4 to 8.7 ) in the first $24 \mathrm{~h}$ and basically stabilized after $72 \mathrm{~h}$. At the end of the immersion tests (after 30 days), the $\mathrm{pH}$ was 9.04 for pure magnesium and 8.15 for $\mathrm{MAO}$-coated magnesium. Hydrogen evolution (Figure 5B) had a similar trend to the $\mathrm{pH}$ value. In the early stage of immersion, pure magnesium reacted with SBF acutely and a rapid generation of bubbles was observed, indicating a fast rate of hydrogen evolution. After $48 \mathrm{~h}$ immersion, however, fewer bubbles appeared, suggesting that the reaction had slowed down and that the rate of hydrogen evolution had decreased. This could be due to corrosion films, including $\mathrm{HA}$ and other phosphates, which had a protective effect and hence retarded further degradation. However, hydrogen evolution was not found in any of the stages of immersion in the MAO-coated samples. Figure $5 \mathrm{C}$ shows the corrosion rates of MAO-coated and uncoated magnesium over time. The corrosion rate of magnesium was high in the first $24 \mathrm{~h}$ and subsequently dropped rapidly, then stabilized after 7 days of immersion. However, the corrosion rate of MAOcoated magnesium remained stable during the immersion tests. The results of the immersion tests were in accordance with those of the electrochemical measurements.

\section{In vitro loss of mechanical integrity}

The influence of in vitro degradation on the tensile strength of both samples is demonstrated in Figure 5D. The tensile strengths of both MAO-coated and uncoated samples were similar before immersion (i.e., time point 0 ). However, the strength of the uncoated samples decreased rapidly in the early stage of degradation, and descended slightly as the immersion period increased. This may be due to the protective effect of the corrosion products formed on the surface of samples during degradation. Meanwhile, the strength of MAO-coated samples stayed constant between the 6-h and 30-day time points. The tensile strength of the coated sample remained at approximately $165 \mathrm{MPa}$ after 30 days of immersion; however, that of the uncoated sample dropped to $140 \mathrm{MPa}$. Therefore, the MAO coating kept magnesium at a constant tensile strength for a period of time.

\section{Cytotoxicity assessments}

The viability of Saos- 2 cells after 24,48 , and $72 \mathrm{~h}$ incubation is shown in Figure 6. There was no significant difference between the absorbance values of cells in the extracts and those in the negative control. As a positive control, the viability of cells incubated in 5-fluorouracil was significantly reduced. Otherwise, cell proliferation was determined by fluorescent staining. Figure 7A-G shows that the morphology of Saos-2 cells cultured in different extracts after $72 \mathrm{~h}$ incubation was normal and healthy, similar to that of the negative control, but the positive control revealed many apoptotic cells, manifested as nuclear pyknosis (Figure 7H). According to ISO 10993-5:1999 (27), the cytotoxicity of these extracts was Grade $0-1$. In other words, 

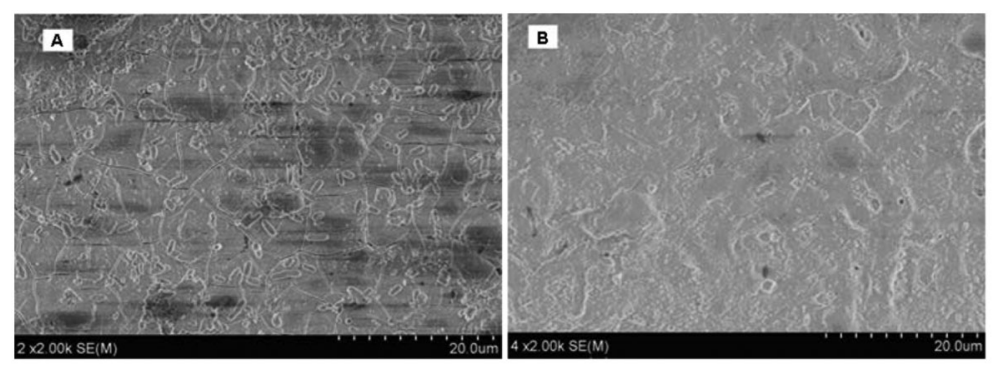

Figure 2. Microstructures of the surface of MAOcoated and uncoated magnesium alloy after immersion for 3 and 14 days, $A, B$, Uncoated and MAO-coated samples after immersion for 3 days, respectively. $C, D$, Uncoated and MAOcoated samples after immersion for 14 days, respectively. MAO: micro-arc oxidation.
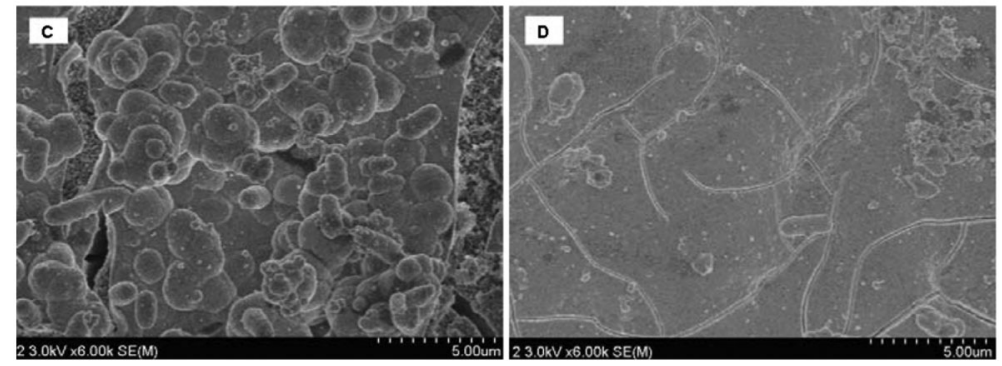

MAO-coated magnesium and uncoated magnesium samples have a level of biosafety that is suitable for cellular applications.

\section{In vivo degradation and biocompatibility experiments}

Biochemical tests. After implantation of MAO-treated and untreated samples, no rabbits displayed inflammation and there were no unexpected deaths. There were no significant differences $(P>0.05)$ in the biochemical indicators of serum magnesium, CREA, BUN, and ALT before and after the operation, which indicated that degradation of the two implants also did not affect kidney and liver functions (Figure 8). These tests demonstrated good biocompatibility of MAO-treated samples in vivo.

Histology evaluation. Histological staining of heart, liver, kidney, and spleen showed that these tissues were normal, which was in good agreement with the results of the biochemical tests and also suggested good biocompatibility of the MAO-treated implant in vivo.

Radiographic evaluation. Radiographs and CT images were taken after 8 and 12 weeks, respectively. The untreated implant started to degrade in the first 8 weeks, as was evident from the observation that the edge of the implant became fuzzy (Figure 9B). No adverse effects due to degradation of the metal implant were observed in the rabbits, which was in agreement with the literature (12). For a clearer image of the implants, CT analysis was used to observe the degradation of the implant. The untreated implant became blurry 12 weeks postoperatively (Figure 9D), so the radiograph and the CT image offered evidence that the untreated implant gradually degraded within the bone. However, all MAO-coated implants were intact throughout the entire implantation period (Figure 9A and C), and no obvious degradation was observed 12 weeks postoperatively.
Bone formation evaluation. a) Bone histology. Figure 10A and $\mathrm{B}$ shows the tissue response to both MAO-coated and uncoated magnesium implants 3 months after implantation, where new bone tissue was observed to form around the implant. All samples showed direct contact with the newly formed bone, and more bone was formed around the MAOcoated implants (Figure 10A) compared to the uncoated sample (Figure 10B).

b) Micro-CT analysis. The in vivo new bone formation during corrosion of the implant in rabbits was studied using micro-CT. Figure $10 \mathrm{C}$ and $\mathrm{D}$ shows 3 -dimensional models of the newly formed bone on both MAO-coated and uncoated implants. The MAO-coated magnesium sample showed more new bone growth after 3 months of implantation (Figure 10C), which was in accordance with the result of bone tissue histology.

\section{Discussion}

Magnesium and its alloys have recently been used in the development of lightweight, biodegradable implant materials. However, the major obstacles to the clinical use of magnesium alloys are its rapid degradation rate and the release of hydrogen gas upon degradation. Therefore, different modifications have been performed on magnesium alloys, one of which is surface modification (28-31). By conducting a suitable surface modification, the corrosion resistance properties of magnesium alloys may be enhanced. MAO, also called plasma electrolytic oxidation or anodic spark oxidation, is a useful anodic oxidation technique for depositing a ceramic coating on the surface of valve metals, such as Al, Ti, $\mathrm{Zr}$, and their alloys $(21,22)$. MAO processes are typically characterized by the phenomenon of electrical discharge on the anode in aqueous solution. In this study, oxide coating layers were formed on 


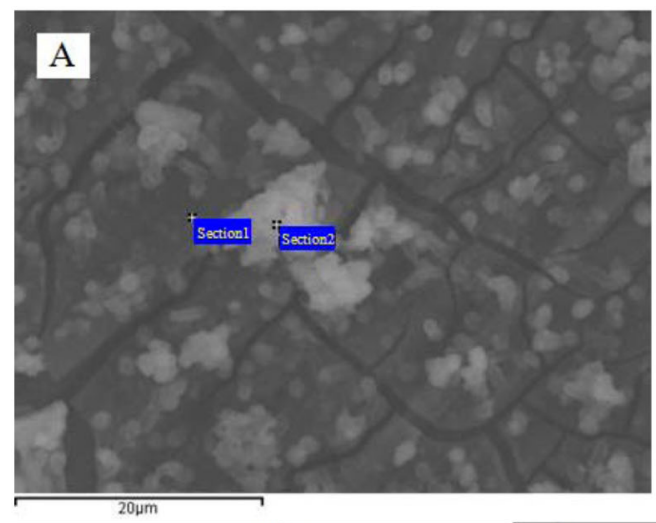

Figure 3. Energy dispersive spectrometry of the corrosion products of untreated $\operatorname{Mg}(A)$, and MAO-treated $\mathrm{Mg}(B)$ after immersion in simulated body fluid for 14 days. MAO: micro-arc oxidation.
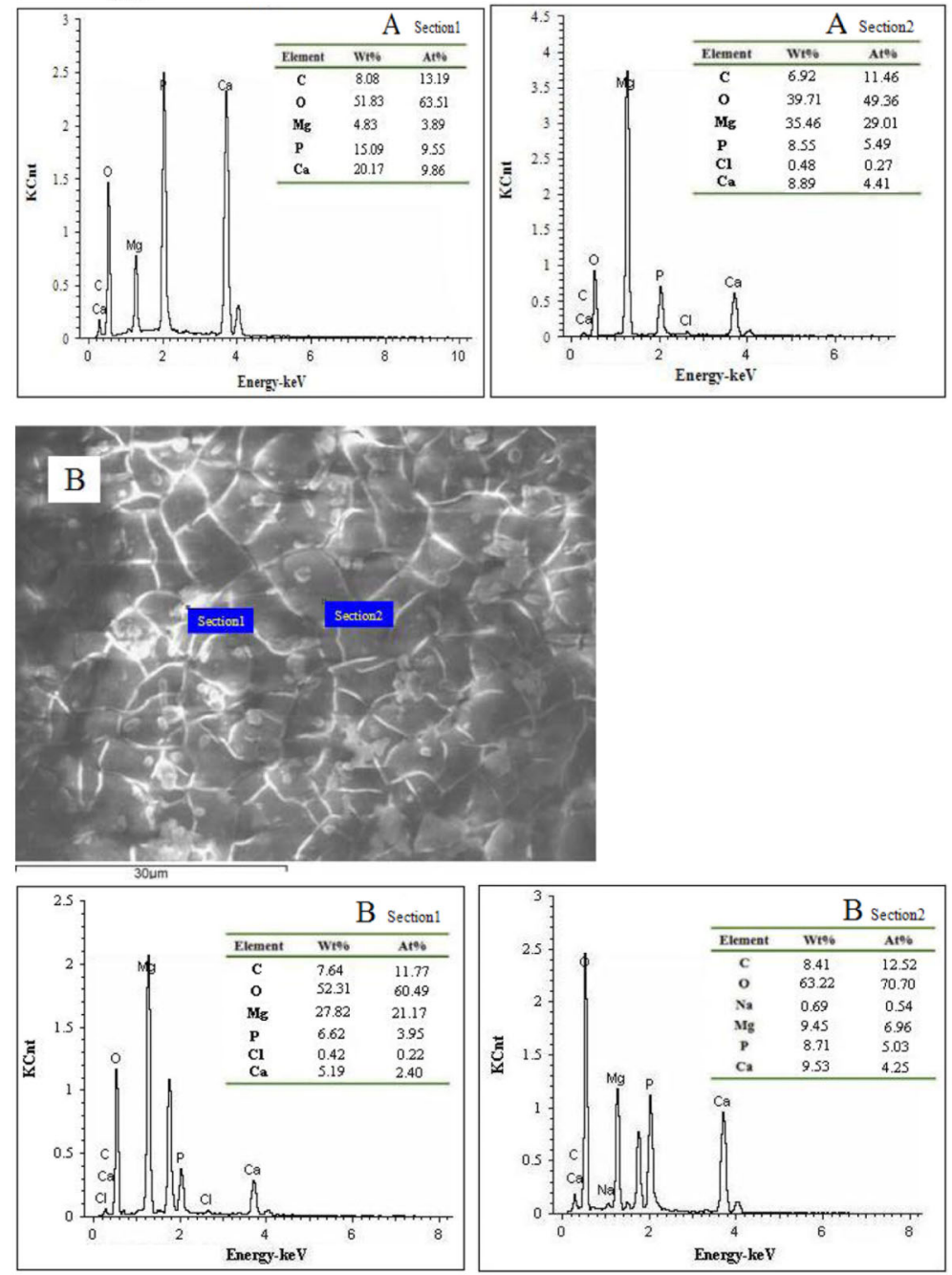

a pure magnesium substrate using $\mathrm{MAO}$, in order to enhance biocompatibility and reduce the degradation rate.

A uniform $\mathrm{MgO}$ coating layer was fabricated on the surface of pure magnesium, and the corrosion properties were evaluated with electrochemical and immersion tests in an SBF. Electrochemical tests showed a significant increase in corrosion resistance for the MAO coating. Immersion tests in SBF solution also revealed an effective reduction in corrosion rate for the MAO-coated samples, and the $\mathrm{pH}$ values of the coated samples always remained at a lower level. The coatings showed mild degradation, whereas the uncoated sample showed relatively obvious 

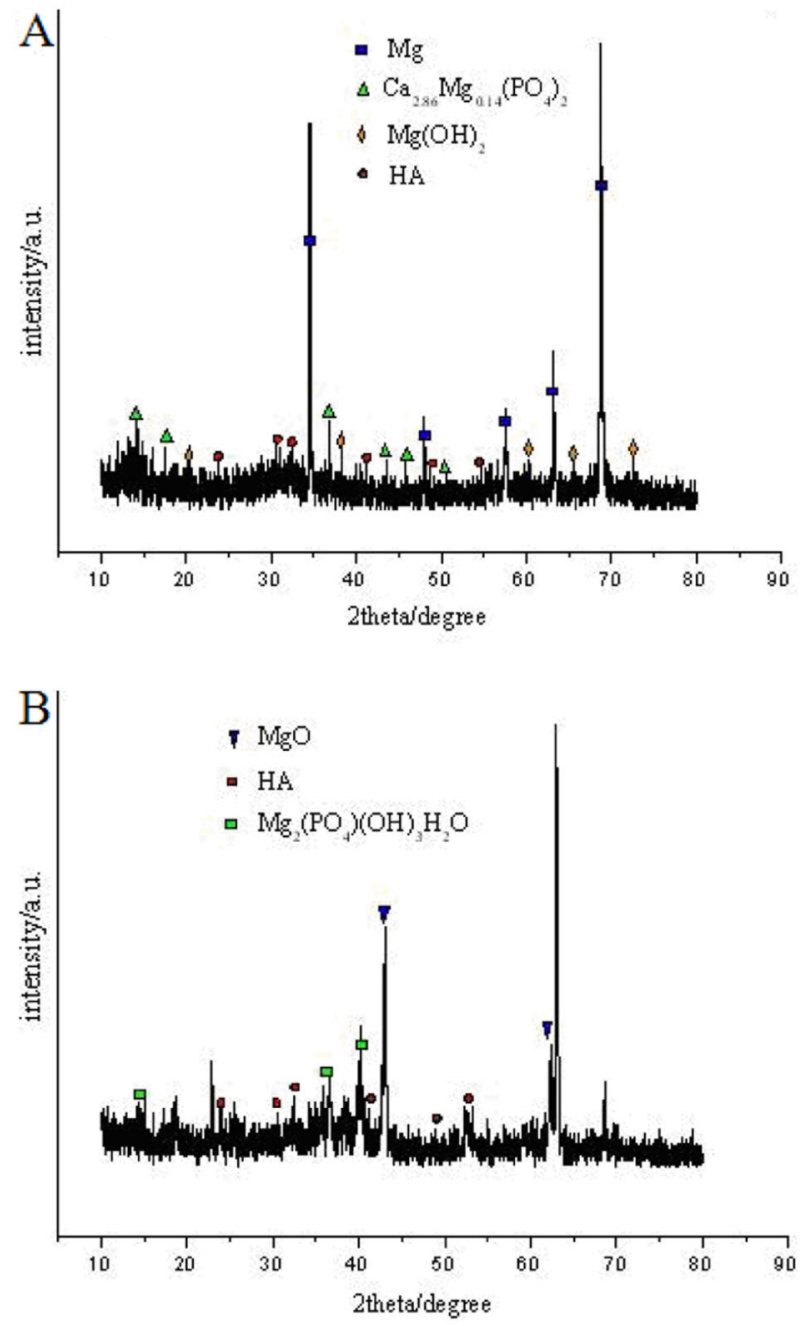

Figure 4. X-ray diffraction analysis pattern of the corrosion products of untreated $\mathrm{Mg}(A)$ and MAO-treated $\mathrm{Mg}(B)$ after immersion in simulated body fluid for 14 days. MAO: micro-arc oxidation.

degradation, and appreciable quantities of $\mathrm{Ca}$ and $\mathrm{P}$ were observed on the surface of the sample after immersion in SBF.

The dissolution of magnesium in aqueous solution (for instance SBF) includes anodic and cathodic reactions (32). The existence of chloride ions $\left(\mathrm{Cl}^{-}\right)$transforms $\mathrm{Mg}(\mathrm{OH})_{2}$ into soluble $\mathrm{MgCl}_{2}$, resulting in excess $\mathrm{OH}^{-}$in the solution (3). Eventually the $\mathrm{pH}$ will rise. In fact, even though the bulk solution has a $\mathrm{pH}$ as low as 4 , the local $\mathrm{pH}$ near the surface of the magnesium could be greater than 10 (33). As a result, if the solution contains ions such as $\mathrm{PO}_{4}{ }^{3-}, \mathrm{Ca}^{2+}$, etc., $\mathrm{HA}\left[\mathrm{Ca}_{10}\left(\mathrm{PO}_{4}\right)_{6}(\mathrm{OH})_{2}\right]$ is likely to nucleate and grow on the magnesium surface owing to the supersaturated condition at high $\mathrm{pH}$ (34). This phenomenon explains the detection of HA by XRD in this study (Figure 4). Moreover, when magnesium ions dissolve into the solution, phosphates containing $\mathrm{Mg} / \mathrm{Ca}$ form and attach tightly to the matrix Taking the excess $\mathrm{OH}^{-}$into consideration, some complicated compounds [represented by $\mathrm{Mg}_{x} \mathrm{Ca}_{y}\left(\mathrm{PO}_{4}\right)_{z}(\mathrm{OH})$ ] might precipitate on the surface. Kuwahara et al. (26) also pointed out that the corrosion products on the surface of magnesium immersed in Hank's solution might be amorphous $\left(\mathrm{Ca}_{0.86} \mathrm{Mg}_{0.14}\right)_{10}\left(\mathrm{PO}_{4}\right)_{6}(\mathrm{OH})_{2}$, a rather complicated compound. In view of the ion concentrations in the SBF used in this study, which are similar to those in Hank's solution, there might be some amorphous phosphates containing magnesium/calcium, as Kuwahara (26) indicated. In fact, a strong background and broadened peaks can be observed in Figure 4, which possibly resulted from the presence of amorphous corrosion products.

The in vitro cytotoxicity of these two metal samples indicated that they are safe to be used as implantable material. Furthermore, bone formation in the in vivo environment was studied using micro-CT. The newly formed bone was found around the implants of both coated and uncoated samples and no adverse effects were found after implantation, which also proved their good biocompatibility. Several studies $(12,13)$ have shown that the corrosion layer containing such magnesium-substituted calcium phosphate compounds on magnesium could promote osteoinductivity and osteoconductivity, predicting good biocompatibility of magnesium. However, in this study a greater amount of new bone formation was found around the MAO-coated samples than around the uncoated samples. This may be due to the rapid degradation and rapidly elevated ambient $\mathrm{pH}$ in the uncoated sample. As a consequence, osteoblasts were unable to proliferate and adhere very well. In addition, Zreiqat (35) reported that magnesium ions could enhance the adhesion of human bone-derived cells and increase the levels of $\alpha 5 \beta 1$ - and $\beta 1$-integrin receptors. Nevertheless, large amounts of magnesium ions released during corrosion of the uncoated sample possibly inactivated new bone formation (36), thereby resulting in less new bone formation around the uncoated sample than around the MAO-coated sample. The coating on the MAO-coated sample reduced the rate of corrosion and the level of magnesium ions, which has been reported to enhance osteoblastic activity and to stimulate the growth of new bone tissue $(1,35)$. Histological analysis also revealed an area of bone formation around these two implants, and there was an absence of inflammation and necrosis, suggesting that there were no toxic effects in the surrounding tissues. The excess magnesium produced by degradation could be excreted by the kidneys, without the kidney, liver, or heart disorders observed during degradation. This correlated with serum biochemical measurements, where no significant differences were observed between serum magnesium levels after implantation for either the coated or the uncoated samples, which are most likely due to homeostatic regulation by the kidney (37). This was a good indication that the coated sample would be safe for in vivo use, considering that, once the coating degraded, the remaining uncoated magnesium alloy would also 

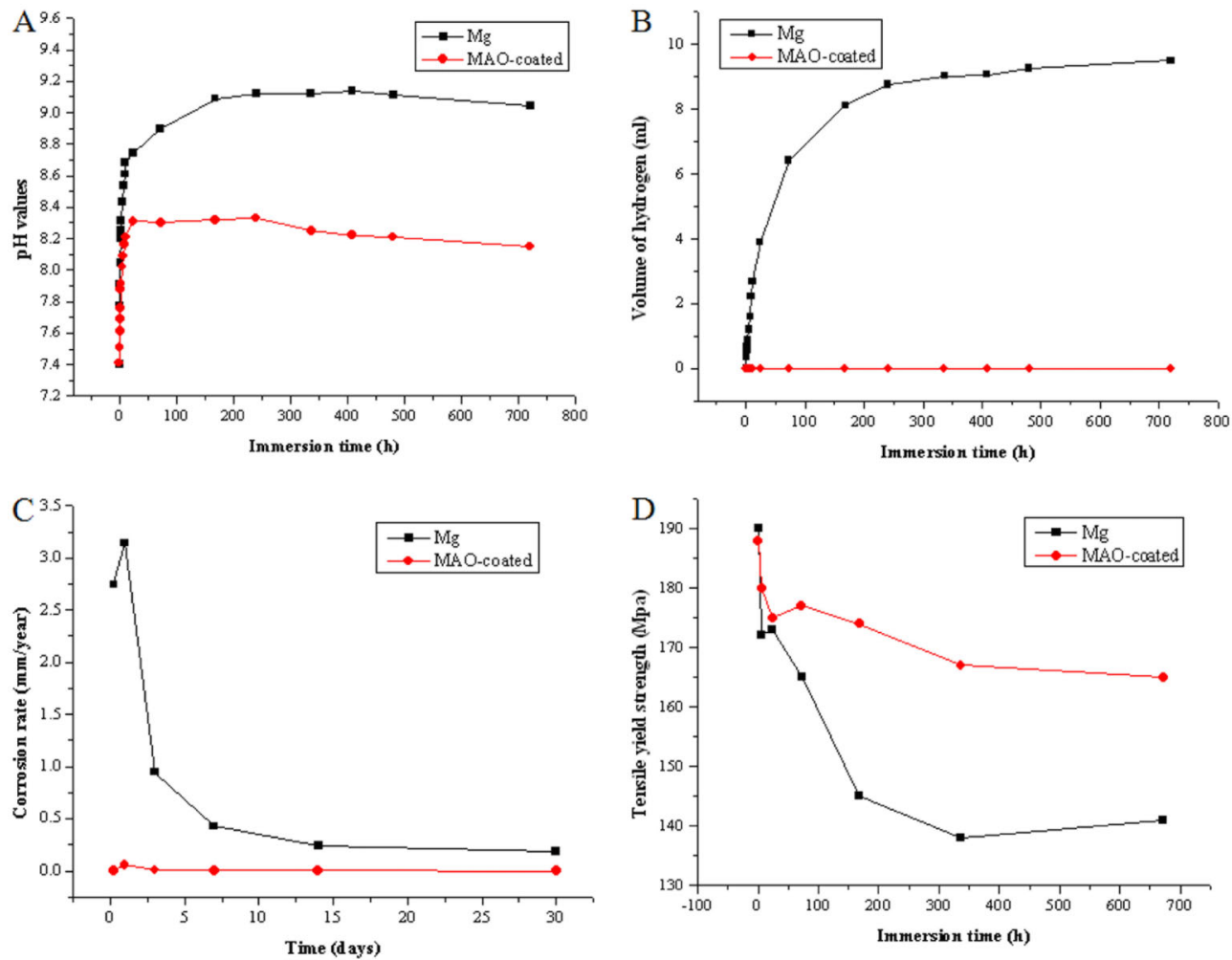

Figure 5. $A, \mathrm{pH}$ of simulated body fluid during 30 days of immersion for $\mathrm{Mg}$ and $\mathrm{MAO}$-coated $\mathrm{Mg}$. $B$, Hydrogen evolution volumes of the two implant materials over time. $C$, Corrosion rate of the two implant materials over time. $D$, Tensile strength of the two implant materials over time. MAO: micro-arc oxidation.

degrade and not induce adverse effects into the localized tissues. These results also implied good in vivo biocompatibility of the MAO-coated implant, which reduced the rate of magnesium ion release and allowed for homeostatic maintenance of physiological magnesium levels. Nevertheless, the mechanism of magnesium ion absorption is still unknown, and whether magnesium ions can be metabolized or will accumulate in certain organs also requires further detailed investigation.

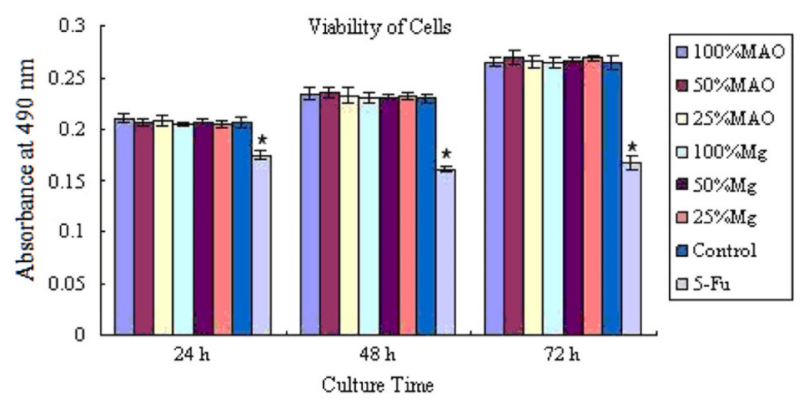

Figure 6 . Saos- 2 cells viability after 24,48 , and $72 \mathrm{~h}$ incubation in the extracts of MAO-coated and uncoated magnesium. ${ }^{*} \mathrm{P}<0.05$, 5 -fluorouracil (5-Fu) compared to all other groups. MAO: micro-arc oxidation.
In this study, it was found that degradation rates of MAO-coated samples were slower than those of pure magnesium. For both MAO-coated and uncoated samples, degradation rates for samples immersed for 30 days were lower than for samples immersed for 3 days, owing to the protective layer on the surface. During the early stage of immersion in SBF, the sample degraded quickly, accompanied by rapid formation of an insoluble protective corrosion layer that retarded degradation, and therefore the corrosion rate of the sample slowed down over time. Under in vivo conditions, slight corrosion occurred on the MAO-coated implant but not on the uncoated implant, which correlated with the in vitro data. This indicated that the MAO membrane was able to prevent metal from having direct contact with body fluid, thereby controlling the degradation rate of magnesium metal in the in vivo environment. However, it is difficult to determine the in vivo degradation rate precisely, because the circumstances in vivo are quite complicated. It should be noted that there were a number of organic components in the in vivo environment, such as proteins and cells. However, the in vitro testing solution was SBF, which mainly contained inorganic ions such as $\mathrm{Cl}^{-}, \mathrm{H}_{2} \mathrm{PO}_{4}^{-}$, and $\mathrm{Ca}^{2+}$. Rettig and Virtanen (38) found that albumin influenced the corrosion process of magnesium alloys in SBF. As a consequence, 

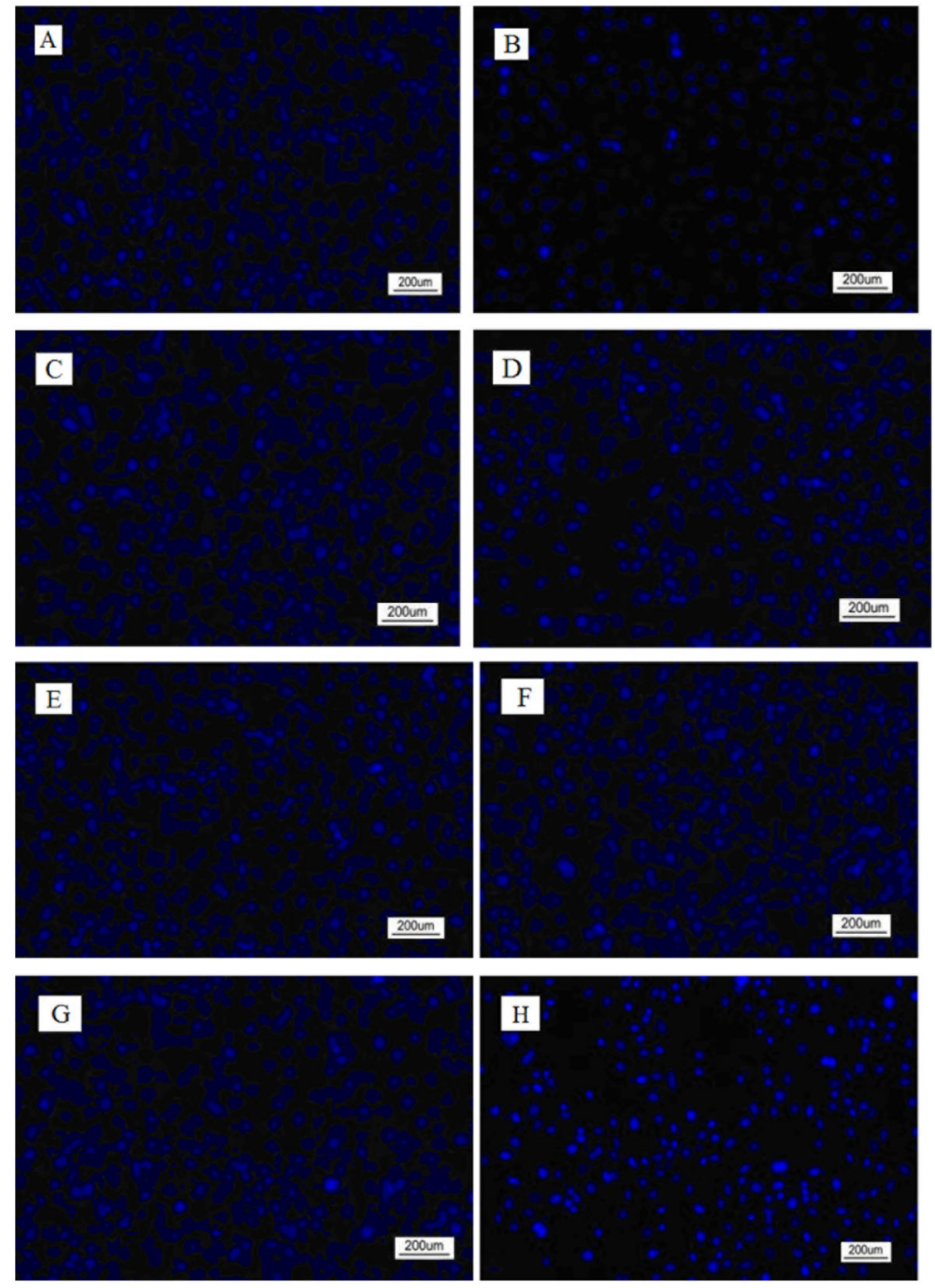

Figure 7. Fluorescent staining of Saos-2 cells after culture in the extracts of MAO-coated and uncoated magnesium for 72 h. Panels $A-G$ show that the morphology of Saos-2 cells cultured in different extracts for $72 \mathrm{~h}$ was normal and healthy, similar to that of the negative control, but the $5 \%$ DMSO positive control revealed many apoptotic cells, manifested as nuclear pyknosis (panel H). A, Negative control; $B, 100 \% \mathrm{Mg}$; $C$, $50 \% \mathrm{Mg}$; D, 25\% Mg; E, 100\% MAO-coated Mg; F, 50\% MAO-coated Mg; G, 25\% MAO-coated $\mathrm{Mg} ; \mathrm{H}, 5 \%$ DMSO positive control. MAO: microarc oxidation. the in vivo degradation products are quite complex. The different compositions of in vitro and in vivo degradation products suggest that degradation of the magnesium alloy will be greatly influenced by the surrounding environment. Thus, if the magnesium alloy is used under different conditions, possible different degradation behaviors must be taken into consideration, otherwise the rate of degradation may be estimated incorrectly. In addition, no gas bubbles were observed on the radiographs throughout the entire experimental period for both MAO-coated and uncoated samples, which was different from other studies $(3,20)$. Possible reasons included the different animal model used, the size of the implant, and the implantation site. The lower surface-to-volume ratio of the sample used in our study would have resulted in a low surface area exposed to the body, thereby reducing the amount of corrosion of the implant. This could have resulted in a decrease in the hydrogen gas release rate, and thus the gas would have been absorbed quickly. As reported by Witte et al. (39), if the degradation rate was slow enough, bubble formation would likely be avoided, because the hydrogen could diffuse into the surrounding tissues.

With regard to the mechanical properties of the samples, MAO treatment would contribute to controlling the degradation process so that mechanical integrity would meet the requirements before the bone has healed. It was found that the tensile strength of both the coated and uncoated samples at the $0 \mathrm{~h}$ time point were similar, since the MAO membrane did not affect the bulk mechanical properties of the magnesium metal. Although the tensile strength of the uncoated sample dropped significantly due to fast corrosion and magnesium ion release during the early time points, the rate of decrease in tensile strength was reduced at later time points owing to the formation of a corrosion layer (40). However, the tensile strength of the MAO-coated samples remained at least $30 \mathrm{MPa}$ higher than that of the uncoated 

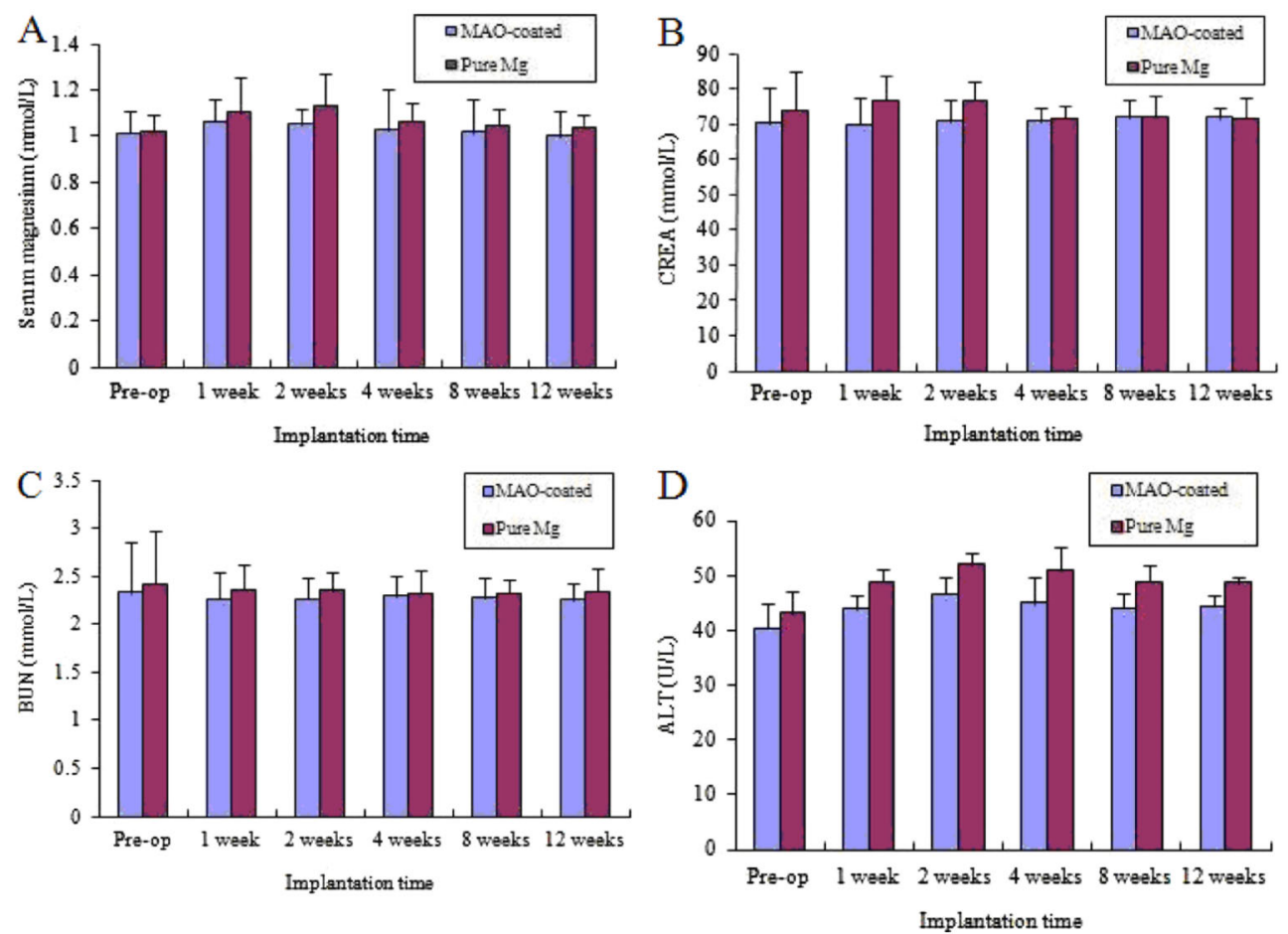

Figure 8. Changes in blood biochemical indicators before and after implantation. $A$, Serum magnesium; $B$, creatinine (CREA); $C$, blood urea nitrogen (BUN); $D$, alanine aminotransferase (ALT). MAO: micro-arc oxidation.

samples after 30 days of immersion, which resulted mainly from the slower corrosion rate of the implant. The mechanical integrity of an orthopedic implant is very important, because when it is used to fix fractured bones it must provide enough mechanical support to the bone throughout
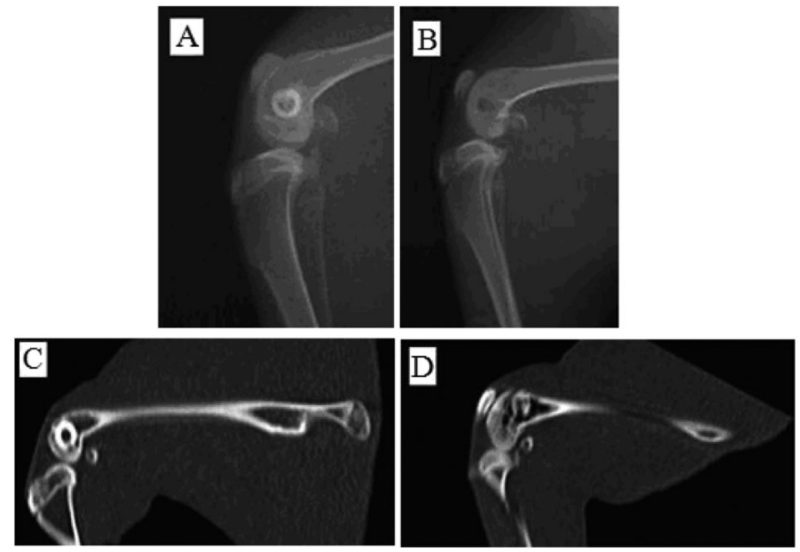

Figure 9. Radiographs of MAO-coated magnesium $(A)$ and uncoated magnesium $(B)$ implants after 8 weeks post-operation; and CT images of MAO-coated magnesium $(C)$ and uncoated magnesium $(D)$ implants after 12 weeks post-operation. MAO: micro-arc oxidation. the healing process. It was noteworthy that MAO treatment slowed down the rate of corrosion of the implant and maintained its strength at about $90 \%$ for 1 month, which is suitable for orthopedic implants, because the strength of the implant was maintained within the first month, allowing for a longer healing period for fractures. However, further longterm studies are needed to confirm this.

In summary, this study demonstrated that the MAO process is an effective method of surface modification for magnesium alloys. The formation of an MAO coating on the implant was shown to reduce the corrosion rate of the implant. In addition, the mechanical properties of the MAOcoated samples were maintained during the immersion test, in contrast to uncoated samples, which is suitable for implant applications because of the protection of the MAO coating layer against corrosion. This is a great advantage for the application of MAO-coated implants in orthopedic procedures, because the slower degradation rate and the retained mechanical strength of the coated implants could allow sufficient time for bone healing. Good cell biocompatibility was found in in vitro cytotoxicity assessments. Moreover, animal implant experiments indicated that there were no disorders of the heart, kidney, liver, and spleen, and no negative effects of magnesium release were observed, indicating that these two implants had good biocompatibility in vivo. Also, larger amounts of new bone formation were found around the MAO-coated samples compared to the 

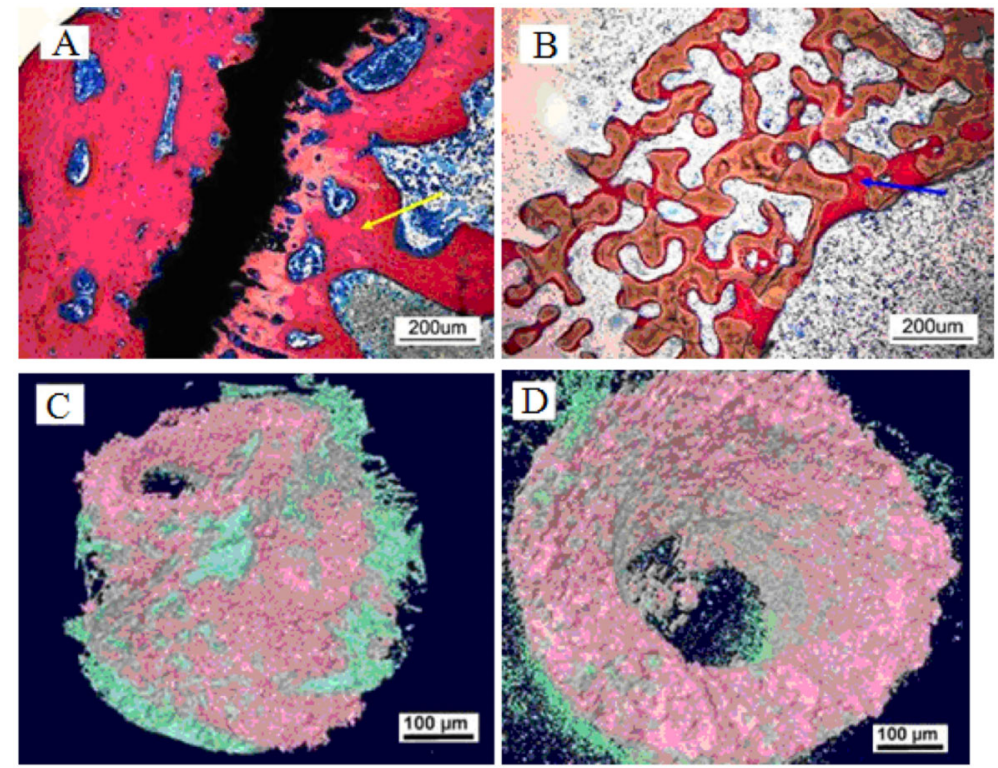

Figure 10. Histological photographs of methylene blue and magenta staining of bone tissue formed around the MAO-coated magnesium implant $(A)$ and the uncoated magnesium $(B)$ implant 3 months after implantation in the greater trochanter where arrows indicate newly formed bone. Micro-CT 3-D reconstruction models of newly formed bone (green in color) on both coated magnesium $(C)$ and uncoated magnesium $(D)$ implants 3 months post-operation are shown. MAO: micro-arc oxidation. uncoated samples. More importantly, the study showed that serum magnesium levels after implantation remained within a normal physiological range for both the MAO-coated implants and the uncoated implants, which indicated that, after degradation of the polymer coating on the implant, further corrosion of the implant would not result in cell toxicity. Nevertheless, further studies are needed to improve the properties of the MAO membrane, such as porosity, hardness, and adhesion to the implant, and additional long-term in vivo studies are required to further validate the

\section{References}

1. Staiger MP, Pietak AM, Huadmai J, Dias G. Magnesium and its alloys as orthopedic biomaterials: a review. Biomaterials 2006; 27: 1728-1734, doi: 10.1016/j.biomaterials.2005.10. 003.

2. Witte F, Fischer J, Nellesen J, Crostack HA, Kaese V, Pisch $A$, et al. In vitro and in vivo corrosion measurements of magnesium alloys. Biomaterials 2006; 27: 1013-1018, doi: 10.1016/j.biomaterials.2005.07.037.

3. Li Z, Gu X, Lou S, Zheng Y. The development of binary Mg$\mathrm{Ca}$ alloys for use as biodegradable materials within bone. Biomaterials 2008; 29: 1329-1344, doi: 10.1016/j.biomaterials. 2007.12.021.

4. Xu L, Pan F, Yu G, Yang L, Zhang E, Yang K. In vitro and in vivo evaluation of the surface bioactivity of a calcium phosphate coated magnesium alloy. Biomaterials 2009; 30: 1512-1523, doi: 10.1016/j.biomaterials.2008.12.001.

5. Witte F, Feyerabend F, Maier P, Fischer J, Stormer M, Blawert $\mathrm{C}$, et al. Biodegradable magnesium-hydroxyapatite metal matrix composites. Biomaterials 2007; 28: 21632174, doi: 10.1016/j.biomaterials.2006.12.027.

6. Zhang E, He W, Du H, Yang K. Microstructure, mechanical properties and corrosion properties of $\mathrm{Mg}-\mathrm{Zn}-\mathrm{Y}$ alloys with low Zn content. Mater Sci Eng A 2008; 488: 102-111, use of MAO-coated implants for orthopedic use.

\section{Acknowledgments}

We are grateful to Dr. Tan Lili for assistance in metal material preparation. We also express our gratitude to Liu Bo, Chen Xiao, and Zhang Fei for their efforts in the animal tests. Research supported by the Major Projects Fund of Hebei Science and Technology Agency (\#12966116d).

doi: 10.1016/j.msea.2007.10.056.

7. Levesque J, Hermawan H, Dub D, Mantovani D. Design of a pseudo-physiological test bench specific to the development of biodegradable metallic biomaterials. Acta Biomater 2008; 4: 284-295, doi: 10.1016/j.actbio.2007.09.012.

8. Wan Y, Xiong G, Luo H, He F, Huang Y, Zhou X. Preparation and characterization of a new biomedical magnesium-calcium alloy. Mater Design 2008; 29: 2034-2037, doi: 10.1016/ j.matdes.2008.04.017.

9. Gray JE, Luan B. Protective coatings on magnesium and its alloys - a critical review. J Alloys Compd 2002; 336: 88-113, doi: 10.1016/S0925-8388(01)01899-0.

10. Troitskskii VV, Dn T. The resorbing metallic alloy 'OSteosinthezit' as material for fastening broken bone. Khirurgiia 1944; 8: 60-63.

11. Kaesel VT, Bach PT, Haferkamp H, Witte F, Windhagen $H$. Apporach to control the corrosion of magnesium by alloying. Proceedings of the Sixth International Conference magnesium alloys and their applications. New York: Wiley-Vch; 2004. p 534-539.

12. Witte F, Kaese V, Haferkamp H, Switzer E, Meyer-Lindenberg A, Wirth CJ, et al. In vivo corrosion of four magnesium alloys and the associated bone response. Biomaterials 2005; 26: 
3557-3563, doi: 10.1016/j.biomaterials.2004.09.049

13. $\mathrm{Xu} \mathrm{L}, \mathrm{Yu} \mathrm{G}$, Zhang $\mathrm{E}$, Pan F, Yang K. In vivo corrosion behavior of $\mathrm{Mg}-\mathrm{Mn}-\mathrm{Zn}$ alloy for bone implant application. J Biomed Mater Res A 2007; 83: 703-711, doi: 10.1002/ jbm.a.31273.

14. El-Rahman SS. Neuropathology of aluminum toxicity in rats (glutamate and GABA impairment). Pharmacol Res 2003; 47: 189-194, doi: 10.1016/S1043-6618(02)00336-5.

15. $\mathrm{Ku} \mathrm{CH}$, Pioletti DP, Browne M, Gregson PJ. Effect of different Ti-6Al-4V surface treatments on osteoblasts behaviour. Biomaterials 2002; 23: 1447-1454, doi: 10.1016/S01429612(01)00266-6.

16. Song G, St John D. The effect of zirconium grain refinement on the corrosion behaviour of magnesium-rare earth alloy MEZ. J Light Met 2002; 2: 1-16, doi: 10.1016/S1471-5317 (02)00008-1.

17. Fan $Y, W u$ G, Zhai $C$. Influence of cerium on the microstructure, mechanical properties and corrosion resistance of magnesium alloy. Mater Sci Eng A 2006; 433: 208215, doi: 10.1016/j.msea.2006.06.109.

18. Yumiko N, Yukari T, Yasuhide T, Tadashi S, Yoshio I. Differences in behavior among the chlorides of seven rare earth elements administered intravenously to rats. Fundam Appl Toxicol 1997; 37: 106-116, doi: 10.1006/faat.1997.2322.

19. Yang W, Zhang P, Liu J, Xue Y. Effect of long-termintake of $\mathrm{Y} 3+$ in drinkingwater on gene expression in brains of rats. J Rare Earth 2006; 24: 369-373, doi: 10.1016/S1002-0721 (06)60126-9.

20. Zhang S, Li J, Song $Y$, Zhao C, Zhang X, Xie C, et al. In vitro degradation, hemolysis and MC3T3-E1 cell adhesion of biodegradable Mg-Zn alloy. Mater Sci Eng C 2009; 29: 1907-1912, doi: 10.1016/j.msec.2009.03.001.

21. Wang $Y Q$, Wu K, Zheng MY. Effects of reinforcement phases in magnesium matrix composites on microarc discharge behavior and characteristics of microarc oxidation coatings. Surf Coat Technol 2006; 201: 353-360, doi: 10.1016/j.surfcoat.2005.11.129.

22. Han Y, Yan Y, Lu C, Zhang Y, Xu K. Bioactivity and osteoblast response of the micro-arc oxidized zirconia films. J Biomed Mater Res 2008; 88A: 117-127, doi: 10.1002/jbm. a.31859.

23. Anonymous. Standardization Administration of the PRC. GB/ $T$ 16886.15-2003: Biological Evaluation of Medical Devices. Part 15. Identification and Quantification of Degradation Products from Metals and Alloys. China: 2003.

24. American Society for Testing and Materials. ASTM-G31-72: standard practice for laboratory immersion corrosion testing of metals. In: Anonymous, Annual Book of ASTM Standards. Philadelphia: American Society for Testing and Materials; 2004.

25. Rondellia G, Torricellib P, Finib M, Giardinob R. In vitro corrosion study by EIS of a nickel-free stainless steel for orthopaedic applications. Biomaterials 2014; 26: 739-744, doi: 10.1016/j.biomaterials.2004.03.012.

26. Kuwahara $\mathrm{H}, \mathrm{Al}-\mathrm{Abdullat} \mathrm{Y}$, Mazaki N, Tsutsumi S, Aizawa $\mathrm{T}$. Precipitation of magnesium apatite on pure magnesium surface during immersing in Hank's solution. Mater Trans 2001; 42: 1317-1321, doi: 10.2320/matertrans.42.1317.
27. ANSI/AAMI. ISO 10993-5:1999. Biological evaluation of medical devices. Part 5. Tests for cytotoxicity: in vitro methods. Arlington: ANSI/AAMI; 1999.

28. Chen F, Zhou H, Yao B, Qin Z, Zhang Q. Corrosion resistance property of the ceramic coating obtained through microarc oxidation on the AZ31 magnesium alloy surfaces. Surf Coat Technol 2007; 201: 4905-4908, doi: 10.1016/ j.surfcoat.2006.07.079.

29. Bakkar A, Neubert V. Improving corrosion resistance of magnesium-based alloys by surface modificationwith hydrogen by electrochemical ion reduction (EIR) and by plasma immersion ion implantation (PIII). Corr Sci 2005; 47: 12111225, doi: 10.1016/j.corsci.2004.06.027.

30. Li GY, Lian JS, Niu LY, Jiang ZH, Jiang Q. Growth of zinc phosphate coatings on AZ91D magnesium alloy. Surf Coat Technol 2006; 201: 1814-1820, doi: 10.1016/j.surfcoat. 2006.03.006.

31. Zhao M, Wu S, An P, Luo J, Fukuda Y, Nakae H. Microstructure and corrosion resistance of a chromium-free multi-elements complex coating on AZ91D magnesium alloy. Mater Chem Phys 2006; 99: 54-60, doi: 10.1016/j. matchemphys.2005.08.078.

32. Song G, Atrens A, St John D, Nairn J, Li Y. The electrochemical corrosion of pure magnesium in $1 \mathrm{~N} \mathrm{NaCl}$. Corros Sci 1997; 39: 855-875, doi: 10.1016/S0010-938X(96) 00172-2.

33. Simaranov A, Sokolova I, Marshakov A, Mikhailovskii Y. Corrosion-electrochemical behavior of magnesium in acidic media, containing oxidants. Prot Metal 1991; 27: 329-334.

34. Jonasova L, Muller FA, Helebrant A, Strnad J, Greil P. Biomimetic apatite formation on chemically treated titanium. Biomaterials 2004; 25: 1187-1194, doi: 10.1016/j.biomaterials. 2003.08.009.

35. Zreiqat $\mathrm{H}$, Howlett $\mathrm{C}$, Zannettino $\mathrm{A}$, Evans $\mathrm{P}$, Schulze-Tanzil $\mathrm{G}$, Knabe $\mathrm{C}$, et al. Mechanisms of magnesium-stimulated adhesion of osteoblastic cells to commonly used orthopaedic implants. J Biomed Mater Res A 2002; 62: 175-184, doi: $10.1002 / j b m .10270$.

36. Serre CM, Papillard M, Chavassieux P, Voegel JC, Boivin G. Influence of magnesium substitution on a collagen-apatite biomaterial on the production of a calcifying matrix by human osteoblasts. J Biomed Mater Res 1998; 42: 626-633, doi: 10.1002/(SICI)1097-4636(19981215)42:4<626::AIDJBM20>3.0.CO;2-S.

37. Vormann J. Magnesium: nutrition and metabolism. Mol Aspects Med 2003; 24: 27-37, doi: 10.1016/S0098-2997 (02)00089-4

38. Rettig R, Virtanen S. Time-dependent electrochemical characterization of the corrosion of a magnesium rare-earth alloy in simulated body fluids. $J$ Biomed Mater Res A 2008; 85A: 167-175, doi: 10.1002/jbm.a.31550.

39. Witte $F$, Ulrich $H$, Rudert $M$, Willbold E. Biodegradable magnesium scaffolds. Part I. Appropriate inflammatory response. J Biomed Mater Res A 2007; 81A: 748-756, doi: 10.1002/jbm.a.31170.

40. Song GL. Recent progress in corrosion and protection of magnesium alloys. Adv Eng Mater 2005; 7: 563-586, doi: 10.1002/adem.200500013. 